\title{
Effect of a Science Camp on the Children's Views of Tentative Nature of Science
}

\author{
Duygu Metin, \\ Department of Elementary Science Education, School of Education \\ Abant Izzet Baysal University, 14280 Bolu, Turkey \\ E-mail: metin_d@ibu.edu.tr \\ Gulsen Leblebicioglu (Corresponding author) \\ Department of Elementary Science Education, School of Education \\ Abant Izzet Baysal University, 14280 Bolu, Turkey \\ E-mail: gulsen@ibu.edu.tr \\ Accepted: February 13 \\ Published: February 22, 2012 \\ URL: http://dx.doi.org/10.5296/jse.v2i1.1348
}

Received: February 9

doi:10.5296/jse.v2i1.1348

\begin{abstract}
This study explored the effectiveness of a science camp on children's views of the tentative nature of scientific knowledge. The method used to do so was a synthesized methodology of explicit reflective guided-inquiry, and several explicit Nature of Science (NOS) activities. The participants were 24 children who were at the $6^{\text {th }}$ and $7^{\text {th }}$ grades. VNOS D questionnaire (Lederman \& Khishfe, 2002) was applied at the beginning and end of the science camp. All of the children were also interviewed in order to validate the questionnaire and enrich the data. The qualitative data were analyzed by using interpretive analysis. The results showed that more children accepted the tentativeness of scientific knowledge at the end of the camp. The children's ideas about tentativeness of scientific knowledge in dinosaurs and meteorology domains were largely affected by the context of the questions especially at the beginning of the science camp.
\end{abstract}

Keywords: Explicit reflective NOS teaching, Guided-inquiry, Nature of science, Science camp 


\section{Introduction}

The importance of understanding the Nature of Science (NOS) is widely accepted by many science educators. The main goal of most of the science education programs in many countries is to develop scientific literacy and understanding the main aspects of NOS is considered to be a key factor in developing scientific literacy (Abd-El-Khalick, 2001). The NOS refers to the values and assumptions inherent to science, scientific knowledge, and the development of scientific knowledge (Lederman, 1992). The tentative nature of scientific knowledge is one of the most emphasized concepts within the nature of science literature. Scientific knowledge, although reliable and durable, is never absolute or certain. This knowledge, including facts, theories, and laws, is subject to change (Lederman, Abd-El-Khalick, Bell, \& Schwartz, 2002). In their study, Lederman and O’Malley (1990) stated that the tentativeness of scientific knowledge is not limited to the recognition of changing scientific knowledge through history. They rather expressed that science draws its tentative and revisionary characteristics from a complex interaction of its assumptions, theories, and methods for construction of scientific knowledge.

Children's views about tentativeness are the most researched aspect of NOS. Most of the research reports about students' views of tentative nature of scientific knowledge showed that children at different grade levels held inadequate understandings of the tentative NOS (Akerson \& Abd-El-Khalick, 2005; Khishfe, 2008; Khishfe \& Abd-El-Khalick, 2002; Khishfe \& Lederman, 2006; Lederman \& O’Malley, 1990; Liu \& Lederman, 2002). Akerson and Abd-El-Khalick (2005) reported that most of the children at fourth grade held naïve views about tentative NOS. They mostly thought that scientific knowledge changes by technological developments. Only some of them realized that scientific knowledge is based on data and scientific knowledge changes when the data change. Khishfe's (2008) study with seventh graders over twelve weeks showed that the children held naïve views about tentative NOS both before and after the study, and it was difficult to develop their tentative NOS views. Most of the children held a misconception of scientists being certain about their knowledge about the dinosaurs and atoms, because they saw them. Some of the children stated that scientific knowledge would change by the addition of new knowledge. Only some of them holding more informed views about tentative NOS and were aware of that scientists inferred their knowledge about dinosaurs and their inferences would change.

Lederman and O’Malley (1990) asked four open-ended questions about tentativeness on a questionnaire and obtained different results regarding tentativeness of science raised from each question. For example, when it was directly questioned if theories might change, more students expressed a tentative view whereas the difference between a law and a theory was asked more students expressed the absolute view. They stated that this may also be interpreted as the students being in transition and thus they had not had a stable view regarding tentative NOS.

Liu and Lederman (2002) reported more positive results with their study conducted with gifted children. Most of them accepted the tentativeness of scientific knowledge and would be able to explain that scientific theories would change because of the limitations of a research or when there is new evidence. Khishfe and Abd-El-Khalick (2002) applied a study 
with sixth graders by implementing explicit NOS activities. They reported that children held inadequate views about the tentative NOS before the study and half of them proposed that scientific knowledge in science books was certain and would not change in the future. Almost all of them stated that scientists are certain about their knowledge on dinosaurs and atom. Their views about the tentative NOS developed by explicit NOS activities and half of them became able to think that scientists could study the events that they could not see and make inferences about them. They also realized that scientists would find new evidence. Thus, scientists could not be certain about their knowledge.

In most of the previous interventions to improve students' tentative NOS views, explicit NOS activities were applied. Since conceptualizing the NOS is a process which based on cognitive learning, most of the researchers argued that attempts to help students develop adequate conceptions of NOS need to be explicit (Akerson, Abd-El-Khalick \& Lederman, 2000; Akerson \& Volrich, 2006; Lederman, 2007; Lederman, Abd-El-Khalick, Bell \& Schwartz, 2002; Schwartz, Lederman \& Crawford, 2004). Explicit approaches were also found to be more effective than implicit approaches in improving learners' views of NOS (Abd-El-Khalick \& Lederman, 2000; Khishfe, 2008; Khishfe \& Abd-El-Khalick, 2002). Explicit approaches have flourished in recent years. In two studies (Akerson \& Donnely, 2010; Akerson \& Volrich, 2006) NOS teaching was embedded in science content and NOS aspects were made explicit while learning the specific science content by asking the students to reflect on how what they did resembled what scientists do. They reported positive changes in first and second graders' understanding of tentative NOS. Although most of them thought that scientific knowledge do not change at the beginning of the instruction, most of them stated that scientific knowledge would change, since scientists would change their minds. Few of them realized that scientists change their minds when they have new ideas or find new evidence.

Since implicit inquiry was found to be ineffective for developing students' understanding NOS aspects (Khishfe \& Abd-El-Khalick, 2002; Meichtry, 1992), explicit inquiry applications were also reported (Schwartz, Lederman \& Crawford, 2004). Khishfe (2008) investigated the development in $7^{\text {th }}$ grade students' NOS views in the context of an explicit inquiry-oriented instructional approach. In this study, students were engaged in inquiry-oriented activities that were followed by reflective discussions of NOS. Khishfe found that students' views of the four targeted NOS aspects (tentative, empirical, inferential, and creative) significantly changed from pre- to post-instruction. In other studies, reflection was sometimes added to explicit inquiry, as in Project ICAN (Lederman \& Lederman, 2004).

In conclusion, NOS teaching is evolving toward enriching methodologies to teach NOS aspects explicitly. Clough (2006) called explicit NOS activities such as black box, cubes, and puzzles as 'decontextualized explicit NOS instruction'. On the other hand, activities related to dinosaurs in which NOS teaching was made explicit in a context were called 'contextualized explicit NOS activities'. Contextualized explicit NOS teaching may also be teaching NOS in a way of embedding in science content or in inquiry laboratory activities (Clough, 2006). Clough proposed that NOS instruction would be more effective if teachers deliberately scaffold classroom experiences and students' developing NOS understanding back and forth 
along the decontextualized/contextualized explicit NOS instruction continuum.

\section{Rationale for the Study}

This study was a study of combining explicit reflective NOS activities and explicit reflective guided-inquiry at the nature to teach NOS aspects. The authors thought that explicit NOS activities show aspects of NOS in a simple and understandable way, but they don't anchor aspects of NOS to scientific process to a great extent. Scientific process is the inquiry of the questions about the world and the aspects of NOS flourished during scientists applying scientific process throughout the history. Thus, inquiry would be a more authentic context to relate aspects of NOS to children's lives. Explicit NOS activities would be integrated to make the aspect of NOS that children lived during their inquiry process explicit and reflect about their understanding about NOS aspects under consideration. Such synthesized methodology of explicit reflective guided-inquiry and explicit reflective NOS activities is being used in recent research (Akerson \& Donnely, 2010). The methodology of the study was applied at a science camp.

\section{Research Question}

The research question which guided the present study was "what is the influence of a summer science camp program which combines explicit reflective authentic guided-inquiry and explicit reflective NOS activities on children's views of tentative NOS?”.

\section{Method}

The science camp was conducted on July, 4-13, 2008 by a team of science educators including the researchers. The science camp was carried out at a village hotel which was located near a forest. The purpose of the summer science camp program was to introduce science and NOS aspects to the children. The main method used in the science camp program was a combination of explicit reflective authentic guided-inquiry to learn scientific process and experience NOS aspects, and explicit NOS activities to make NOS aspects explicit and relate NOS aspects to their inquiry process. Clough's (2006) suggestions for effective NOS instruction were taken into consideration in developing the program. As it can be seen in the science camp program presented in Table 1, NOS instruction started with decontextualized activities, DAST (Chambers, 1983) and Water Machine Black-box activity. Decontextualized, moderately contextualized and highly contextualized explicit reflective NOS activities were spread out over the program in the following days in a way that children's learning about NOS instruction was scaffolded back and forth in a decontextualized/contextualized continuum. NOS instruction ended with two decontextualized activities, Tricky Tracks and The Cube (Lederman and Abd-El-Khalick, 1998) to summarize NOS aspects in a general way after their specific inquiry process. Each type of activity is described below.

\subsection{Decontextualized Explicit Reflective NOS Activities}

The program started with DAST (Chambers, 1983) to elicit the children's ideas about science and scientists. This was followed by the Water Machine black-box activity (Lederman and Abd-El-Khalick, 1998). They were informed that they would work as scientists and study an event that they could not see. They were asked to model what was inside the box. They 
shared their models and reflected on their ideas about science and scientists.

The explicit NOS activities implemented in the program were Black Box, Real Fossils, Real Science, Young Woman or Old Woman, The Hole Picture, Tricky Tracks and The Cube (Lederman and Abd-El-Khalick, 1998). Debriefing after each activity was also done to make NOS aspects explicit.

\subsection{Moderately Contextualized Explicit Reflective NOS Activities}

In the Research I and Research II sessions, the children learned about variables and designing experiments. In the first session, the instructor explained independent, dependent, and controlling variables in the context of the pendulum. Then, the children worked in small groups and designed an experiment to search the effect of a variable of their choice on the swing of a pendulum. They shared their experiments at the end of the session and reflected their understanding of science and NOS aspects.

In Research II, they were asked to find out the optimum conditions for a balloon to reach the space station which was a point on a string tied to a tree. They worked in small groups with different pieces of string on trees and tested the effect of different variables such as shape of the balloon, the amount of air in the balloon etc. At the end, they competed with their rockets on the same piece of string. Debriefing discussions regarding NOS aspects were also conducted. 


\section{MInstitute ${ }^{\text {Mank }}$}

Table 1. The Science Camp Program

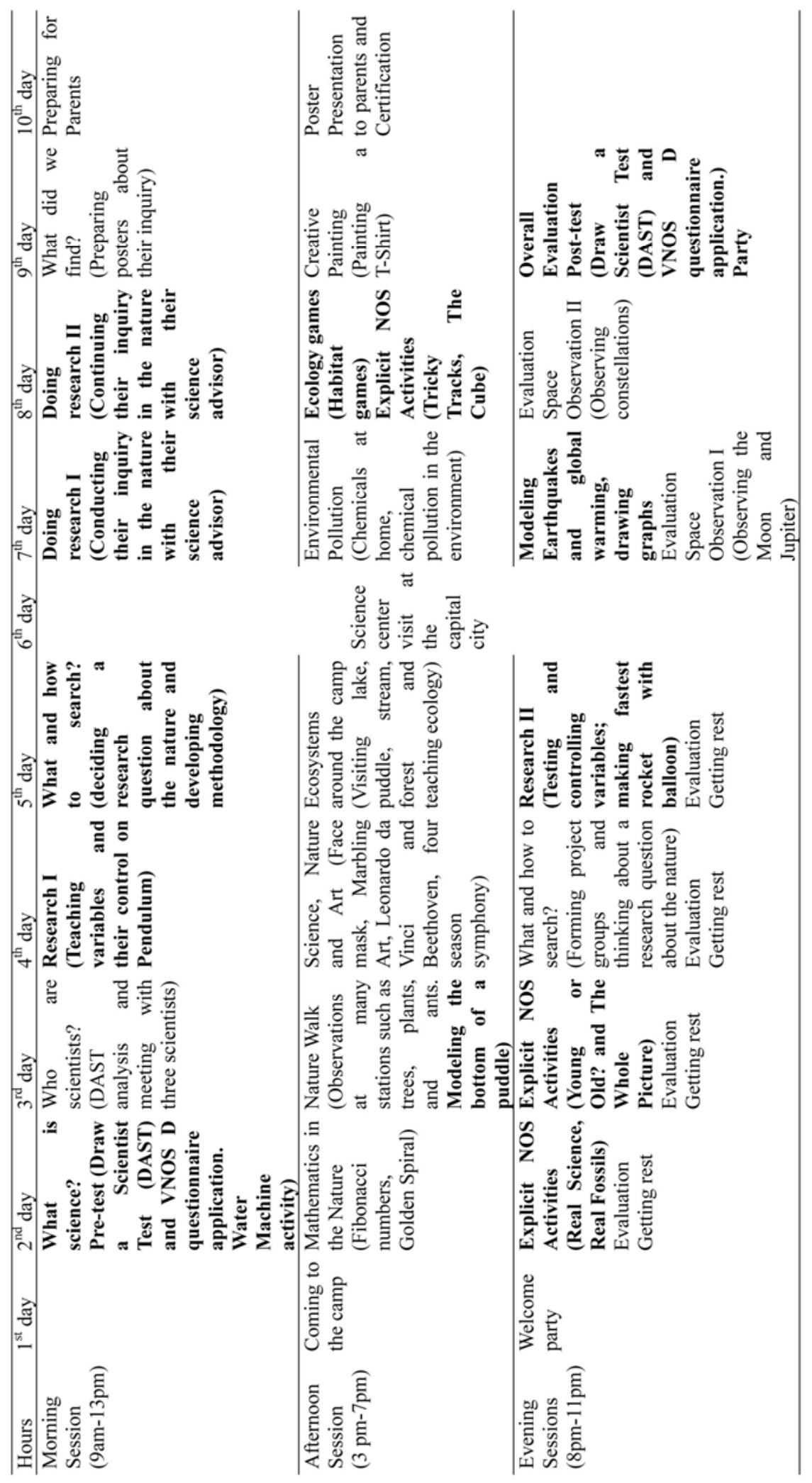


In Modeling the Bottom of a Puddle activity, the students in small groups working with an instructor measured the depth of a puddle from different points marked with intersection points of strings aligned on the surface of the puddle. They entered $\mathrm{x}, \mathrm{y}, \mathrm{z}$ data for each point to a spread sheet program and drew a 3D graph which models the shape of the bottom of the puddle. Then, they aligned more strings between the existing strings on the puddle and measured the depth of the puddle from new intersection points. They again drew 3D graph of their data and compared two models of the bottom of the puddle and talked about NOS aspects.

Another activity was Modeling Earthquakes activity. Working in small groups, the children were given a long list of devastating earthquake data recorded over many years in the geographic location of the country. They were also given a map of the country and asked to mark each earthquake data on the map. Then, they were given the professional earthquake map of the country showing all earthquake regions. They reached the conclusion that their map showed the first degree earthquake regions of the country. They were asked to predict the closest possible future earthquake for a few cities to make them think about the pattern in the earthquake data for specific cities. Then, they were asked about how scientists would have formed the professional earthquake map and how they make predictions about future earthquakes. They reflected on their NOS understanding.

\subsection{Highly Contextualized Explicit Reflective NOS Activity}

One activity was considered as highly contextualized activity; guided-inquiry in the nature. The children conducted an inquiry to answer a question that they asked about nature. They worked at different locations depending on the subject of their inquiry and collected first-hand data through observation or measurement. Then, they organized their data, interpreted their data, and answered their research question. Each group prepared a poster explaining their research process and they presented to their families on the last day. The science advisors guided their work throughout their inquiry into nature and also probed the children's thinking about NOS aspects whenever appropriate.

\section{Participants}

Participants were 24 elementary grade children who were from ten different elementary schools. Thirteen of them were at $6^{\text {th }}$ grade and eleven of them were at $7^{\text {th }}$ grade. Eleven of them were girls and thirteen of them were boys. The ages of participants were twelve and thirteen. The children were selected according to their interest in science. Science teachers' suggestions were taken into consideration during the selection. The children participated to the science camp voluntarily.

\section{Data Collection}

A qualitative methodology was applied in this study. Views of Nature of Science Version D (VNOS D) (Lederman \& Khishfe, 2002) was applied to examine the children's views about the aspects of the NOS at the beginning and end of the camp. All children were also interviewed to validate the questionnaire. VNOS-D consists of seven open-ended questions which examine several aspects of NOS, but data regarding tentative NOS were mainly emerged from three questions: 
1) Scientists produce scientific knowledge. Some of this knowledge is found in your science books. Do you think this knowledge may change in the future? Explain your answer and give an example.

2) (a) How do scientists know that dinosaurs really existed?

(b) How certain are scientists about the way dinosaurs looked?

(c) Scientists agree that about 65 millions of years ago the dinosaurs became extinct (all died away). However, scientists disagree about what had caused this to happen. Why do you think they disagree even though they all have the same information?

3) In order to predict the weather, weather persons collect different types of information. Often they produce computer models of different weather patterns.

(a) Do you think weather persons are certain (sure) about these weather patterns?

(b) Why or why not? (VNOS D, Lederman \& Khishfe, 2002)

\section{Data analysis}

The data were analyzed by interpretative analysis (LeCompte \& Preissle, 1993). Interview and questionnaire data for each child were combined. First author coded the data and second author checked the coded data and they resolved the discrepancies by discussing and reaching a consensus. Then, they categorized the coded data inductively until all data were organized. They also interpreted the data together.

When the researchers examined the data a few times in detail, they noticed that there was no consistency in the children's ideas about the science books question, the dinosaurs and meteorology questions. The types of the questions were different. The science book question examined the tentativeness of scientific knowledge directly, not in a related context. Moreover, it focused on only the tentativeness of scientific knowledge, not how scientific knowledge was constructed. On the contrary, the second and third questions examined the tentative nature of science in the context of dinosaurs and meteorology. Moreover, these questions also aimed to elicit the children's ideas about how scientists construct knowledge and how they can be certain about their knowledge. The researchers thought that the pattern in the first question was different from the pattern in the second and third question. Thus, two coding schemes were developed by the researchers, one for the first, and other one for the second and third. Another support for separate analysis of general and context-specific NOS conceptions comes from Urhahne, Kremer, and Mayer (2011). They suggested analyzing general and context-specific NOS conceptions separately, since these conceptions tap different levels of NOS understanding (pp. 725).

Such coding process is different from common coding in NOS literature in which respondents' ideas are assigned into pre-defined two categories of naïve and informed. Such coding is a deductive way of organizing data, but should not be the only way of coding in NOS research. Inductive coding would be another way of coding which enriches and deepen the analysis of respondents' ideas. Each coding scheme emerged from the data in this study is defined below. 
Coding Scheme of Children's Views of Tentative NOS in Science Books

The researchers thought that there was a pattern in the degree of children's conceptualization of the tentative nature of scientific knowledge in science books. They formulated the following four hierarchical categories ranging from more informed to less informed views of the tentativeness of scientific knowledge in science books.

Data-based Explanations: Children in this category indicated that scientific knowledge would change if new data are collected.

Technological Viewpoint in Explaining Tentativeness: Children in this category indicated that scientific knowledge would change because of technological innovations and new discoveries.

Superficial Acceptance of Tentativeness: This category includes such responses in which the change in scientific knowledge was superficially stated without further explanation. They sometimes just give an example for the change.

Non-tentative: This category indicates the idea that scientific knowledge does not change.

Coding Scheme of Children's Views of Tentative NOS in Dinosaurs and Meteorology Domain

The children's responses to the dinosaurs and meteorology questions were first categorized according to whether they accepted the tentativeness of scientific knowledge in both questions, accepted it in one question, but not in the other question; or do not accept tentativeness in either question. These categories were named as 'accept tentativeness in all domains', 'accept tentativeness in some domains', and 'do not accept tentativeness in any domain'. On re-examination of the children's responses in each category, it was observed that the ideas of the children who accepted tentativeness in all domains differed in the degree of generalization of their explanations for the tentativeness of scientific knowledge. Thus, the responses in this category were further categorized into three categories as generalized explanations, in progress toward generalization, and context-bounded explanations. For further clarification, each category was described below.

Accept Tentativeness in All Domains: Children in this category were able to explain that scientists would not be certain about scientific knowledge which they constructed in both the dinosaurs and meteorology domain. However, they differed in their explanations for tentativeness of scientific knowledge. They were further categorized into three categories.

Generalized Explanations: Children in this category were able to explain the degree of tentativeness of the scientific knowledge based on data (amount of data, nature of data, and change in the interpretation of existing data). Their responses indicated that they generalized the tentativeness of scientific knowledge to all domains and accepted that all types of scientific knowledge in any domain are subject to change.

In Progress toward Generalization: Children in this category were able to explain the degree of tentativeness of the scientific knowledge based on data (amount of data, nature of data, and change in the interpretation of existing data). However, their ideas of tentativeness of scientific knowledge were mainly affected by the nature of domain. For example, not being able to see the dinosaurs was the main concern for them in 
deciding tentativeness of knowledge about dinosaurs, whereas frequent changes in weather conditions was the main concern in deciding the tentativeness of scientific knowledge about meteorology.

Context-bounded Explanations: Children in this category were able to explain the degree of tentativeness of the scientific knowledge based on only the nature of domain. For example, not being able to see the dinosaurs was the only concern for these children in deciding tentativeness of knowledge about dinosaurs whereas frequent changes in weather conditions was only concern for the children in deciding the tentativeness of the scientific knowledge about meteorology.

Accept Tentativeness in Some Domains: The children in this category accepted that scientists would not be certain about the knowledge which they produced in one domain, but not in the other.

Do not Accept Tentativeness in any Domain: This category includes children who accepted that scientists would be certain about the knowledge which they produced in both domains.

\section{Results}

Children's views of the tentative NOS were described and illustrated in two sections corresponding to two different coding schemes described previously. The children's names are pseudonyms.

\section{Children's Views of Tentative Nature of Scientific Knowledge in Science Books}

Figure 1 shows the children's views of the tentative nature of scientific knowledge in science books.

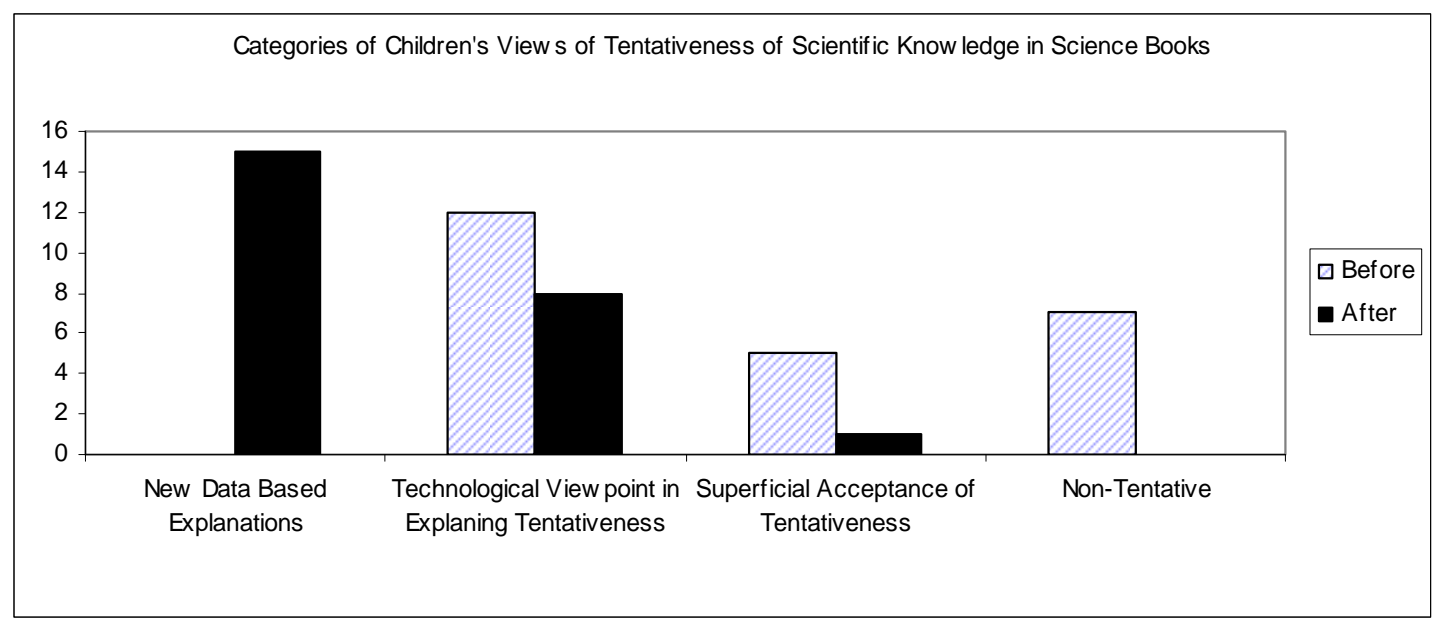

Figure 1. Children's Views of the Tentative Nature of Scientific Knowledge in Science Books at the Beginning and End of the Science Camp

It can be seen that most of the children fell into the category of technological viewpoint in explaining tentativeness at the beginning of the science camp. They thought that scientific knowledge in science books would change in the future because of technological innovations and new discoveries. They considered technological developments when they were deciding the tentativeness of scientific knowledge as it was evident in the following quote: 
This knowledge might change because technology improves everyday. Thus, we have the opportunity to examine the knowledge elaborately as new devices are invented. The atom model is an example. The scientist who first discovered the atom proposed an atom model. Later, Dalton proposed another atom model. This is the result of developments in technology. He examined it better with technology and then attained new knowledge. (Sinan)

The second common idea among children at the beginning of the science camp was the non-tentative (absolute) view. These children thought that scientific knowledge in science books would not change in the future. Two of the children who did not accept the tentativeness of scientific knowledge in science books thought that scientific knowledge is proposed if it is certain. Some children stated that each generation would learn different scientific knowledge if it changes and some of them said that they did not experience or observe any change in the scientific knowledge in science books. Following quotes are examples of such children's ideas:

In my opinion, it cannot change, because, scientists do not propose scientific knowledge if they are not $100 \%$ sure about it. (Murat)

In my opinion, it does not change, because, if we look at the books published five or six years ago, the knowledge in these books is the same as the ones in more recent books. (Cagla)

The rest of the children superficially accepted the tentativeness of scientific knowledge without much understanding. Although they accepted the tentativeness of scientific knowledge in science books, they could not give any further explanations to explain how scientific knowledge changes. Generally, they just gave an example.

I think scientific knowledge will change in the future. For example, atom models have been changed from past to present. (Bora)

In summary, even though most of the children thought that scientific knowledge in science books would change in the future at the beginning of the science camp, they were not aware of that scientific knowledge would change when scientists find new data or they reinterpret available data. So, technological developments were the main concern for most of the children when they were thinking about tentativeness of scientific knowledge in science books.

The children's views of the tentative nature of scientific knowledge in science books changed considerably throughout the science camp. A remarkable amount of the children had absolute views of scientific knowledge at the beginning of the science camp; whereas no children left with this idea at the end. Furthermore, fewer children proposed only technological developments in explaining tentativeness or superficially accepted the tentativeness of scientific knowledge at the end of the science camp. In addition to this positive change, most of the children started to use data in their explanations of the change in scientific knowledge. Their ideas were categorized and labeled as data-based explanations. Children realized the role of the data in tentativeness of scientific knowledge. Thus, they began to better explain how scientific knowledge changes. More than half of the children explained that scientific knowledge would change if new data were collected. 
Scientists produce scientific knowledge based on data that they have. As time goes on, they will make more observations and will have more data. Because of this new data, previous scientific knowledge will also change. (Yonca)

As in the quote, most of the children realized the importance of data for scientists when they construct scientific knowledge. They conceptualized that making more observations and having more data resulted in a change in scientific knowledge. Some children also realized the degree of the tentativeness of scientific knowledge. They stated that some scientific knowledge changes completely whereas some of them changes when new scientific knowledge is added. Two children even indicated that paradigmatic changes would cause a change in scientific knowledge.

Scientific knowledge will change. Scientific knowledge produced at any time depends on the perspectives, experiments, interpretation, imagination, and social environment at that time. Any change in these aspects in the future will also cause a change in the scientific knowledge. (Gulden)

At the end of the science camp, children began to explain better why scientific knowledge changes. In addition to technological developments, they realized the importance of the amount of data and the addition of new data in explaining the change in scientific knowledge in science books. They focused on the collection of new data, the amount of collected data, and change in data or its interpretation in their explanations of the tentativeness of scientific knowledge.

\section{Children's Views of Tentative Nature of Scientific Knowledge in Dinosaurs and Meteorology Questions}

The frequencies of the categories are seen in Figure 2.

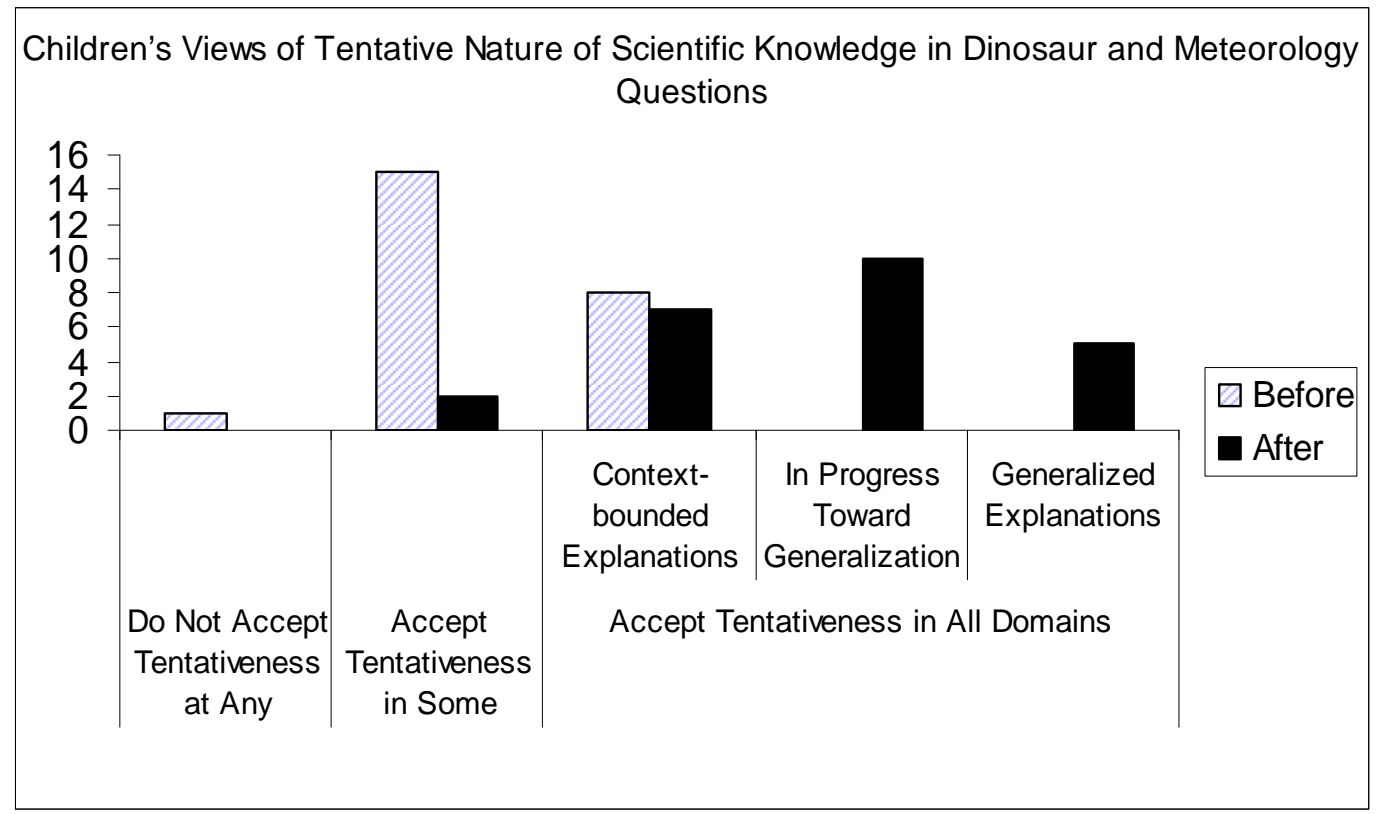

Figure 2. Children's Views of Tentative Nature of Scientific Knowledge in Dinosaurs and Meteorology Questions 
At the beginning, eight children accepted tentativeness of scientific knowledge in all domains. Most of the children accepted the tentativeness of scientific knowledge in some domains. One child did not accept tentativeness in any domain.

It was seen that more than half of the children elucidated transitional views of the tentative nature of scientific knowledge about dinosaurs and meteorology. They seemed to believe that scientific knowledge in some research areas would change, but scientific knowledge in other research areas is certain or absolutely true. So, they were categorized into the category of “accept tentativeness in some domain”. For example, Aslı stated that scientific knowledge about dinosaurs is certain or true, but scientific knowledge about weather is not.

C: Scientists know the color, shape, skin, and tail features of the dinosaurs by using the remaining fossils, books from earlier ages, and by conducting experiments about them. They are certain about the shape of the dinosaurs, because, they have accumulated their knowledge for years and they have improved science. Thus, they are completely sure about the shape of the dinosaurs.

I: You said that they are completely certain.

C: Yes. Because, they have struggled for years. They have made experiments and have examined what they found out. (Aslı)

To me, they are not certain about the weather patterns, because, weather is always changing. Computers might also make a mistake. The question mentions making predictions. Scientists do not propose certain results. They might miss out some parts of the investigation. Thus, I think they are not certain. (Aslı)

One third of the children accepted tentativeness both in dinosaur and meteorology questions. Although these children seemed to believe that scientific knowledge is not certain and subject to change, they considered the nature of the context when they were deciding about the tentativeness of scientific knowledge about these contexts. For instance, since research about dinosaurs and meteorology were used as contexts in these questions, not being able to see dinosaurs and frequent changes in weather conditions were only concern for these children in deciding the tentativeness of scientific knowledge about dinosaurs and meteorology. So, they could not think of tentativeness of scientific knowledge independent of the nature of context. Thus, these children's ideas were categorized as context-bounded explanations. Following quotes are examples for such explanations:

To me, it is not certain, but it can be $75 \%$ certain. It might be rainy in summer or it might be sunny in winter. It is not certain that what happens in the future. Meteorologists make measurements but weather always changes. (Murat)

C: They (scientists) look at the bone structure and the DNA of the dinosaurs.

I: How certain are scientists about the way dinosaurs looked?

C: It is not certain, but they are close to.

I: How certain are they?

$\mathrm{C}: 70 \%$ 
I: Why they are not completely certain?

C: Since they did not see dinosaurs. No one can construct shape of something that was not seen. (Murat)

Only one child did not accept tentativeness of scientific knowledge in neither dinosaurs nor meteorology questions. This child was categorized into the category of "do not accept tentativeness at any domain". But the reason for this child's idea was trusting science. He believed that scientists could be certain about an issue after searching it many times.

It is not necessary to see them (dinosaurs) to say that their color was green. It can be concluded from the bone cell or anything related to it. So, I think that scientists are certain about that. If you have some information about the dinosaurs, you already do further research. If you have enough information, you already reach a conclusion. So, you become certain about that. (Burak)

Meteorologists make more than one observation to reach a conclusion. For example, if they have evidence, they check it many times. If results are the same, they can reach an absolute conclusion. (Burak)

Similar to the science books question, the children's views of tentative nature of scientific knowledge in dinosaurs and meteorology question improved remarkably throughout the science camp. The science camp extended the children's understanding about the tentativeness of scientific knowledge in these contexts. At the end of the science camp, the children's views of the tentativeness of scientific knowledge about dinosaurs and meteorology were categorized into two general categories: accept tentativeness in some domain and accept tentativeness in all domains. There was no need for the category of "do not accept tentativeness at any domain" at the end of the science camp data. In addition to this positive change, only two children left with the idea of accepting tentativeness in some domain. They thought that scientific knowledge about dinosaurs was subject to change, whereas they thought that scientific knowledge about meteorology are absolutely true because of the technology used in meteorology.

Since almost all children accepted the tentativeness of scientific knowledge in both domains at the end of the camp, their ideas were diverse. Thus, the children's ideas in accepting tentativeness in all domains category were also further categorized into three subcategories: context-bounded explanations, in progress toward generalization, and generalized explanations. Although all of the children in these categories accepted that scientific knowledge is subject to change, there were some differences in the degree of the children's understanding of tentativeness. Positively, except for two children, all of the children seemed to think that scientific knowledge about dinosaurs and meteorology was not certain and that it was subject to change by the time. One third of them provided context-bounded explanations which refer to the effect of context of the question in deciding the tentativeness of scientific knowledge. Positively, almost half of them were in progress toward generalization which indicates that although these children were aware of the importance of the data in tentativeness of scientific knowledge, their views were sometimes affected by nature of the context when they were deciding the tentativeness of scientific knowledge about dinosaurs and meteorology. Following quote is an example: 
The meteorologists are not certainly sure about the weather patterns, because, they construct patterns by using their data. The meteorologists propose ideas by examining their data, because they just have data and their thinking. However, weather might change suddenly. (Giray)

Five children provided generalized explanations. These children were able to explain the tentativeness of the scientific knowledge based on data in both questions. They mentioned the amount of data, the nature of data, and the change in the interpretation of existing data when they were explaining the tentativeness of scientific knowledge. Furthermore, these children generally used general explanations about the way in which scientists engaged in research about dinosaurs, meteorology or other research areas. So, this referred to the generalization of the tentativeness of scientific knowledge to any area of science. Burak was one of these children.

\begin{abstract}
Scientists know about the existence of the dinosaurs by observing, finding fossils, and studying other animals. They try to find relationship between dinosaurs and other animals. Generally, scientists obtain information by observation and by collecting data when they research subjects they don't know. So, the more data scientists have the more capable they are of constructing scientific knowledge. If scientists have more detailed data, they are more certain. (Burak)

I: Do you think meteorologists are certain about the weather patterns?

C: Of course they are not completely certain. If scientists have more data, they can be closer to the true scientific knowledge. For example, we used intersection points of the squares to measure the bottom of the puddle in the puddle activity. When we made smaller squares, we made more measurements and had more data and better able to draw the bottom of the puddle. If we had even smaller squares, we would better find out the cavities in the bottom of the puddle. I mean that if we study in more detail, we would get more clear conclusions. (Burak)
\end{abstract}

\title{
7. Discussion
}

The aim of the science camp was to introduce the nature of science to children with a hybrid methodology of explicit reflective guided-inquiry at the nature and explicit NOS activities. The activities in the NOS instruction were started and ended with decontextualized NOS activities, but there were moderately decontextualized and highly contextualized activities in between to support children's conceptual change regarding NOS aspects. The results showed that most of the children's views about tentative nature of scientific knowledge developed throughout the science camp. Although half of the children entered the camp with an absolute view of scientific knowledge or superficial understanding of tentativeness of scientific knowledge in science books, they all became able to accept the tentativeness of scientific knowledge in science books and explain tentativeness of scientific knowledge based on nature and the amount of data. Similarly, the children's ideas about tentativeness of scientific knowledge about dinosaurs and meteorology developed into data-based and more general reasoning regarding tentativeness of scientific knowledge rather than reasoning based only on specific characteristics of the context of the question. Most of the children accepted the tentativeness of scientific knowledge in one of the dinosaurs or meteorology questions at the beginning of the science camp, but they proposed such reasons as 'scientists not being able to see dinosaurs' and 'weather always changes' while they were deciding the tentativeness of 
scientific knowledge. At the end of the camp, almost all of them accepted tentativeness of scientific knowledge at both questions and most of them progressed gradually toward data-based thinking in deciding the tentativeness of scientific knowledge. Data-based thinking in deciding the tentativeness of scientific knowledge in an area would have helped them in thinking more independent of the context and generalize tentativeness of scientific knowledge to all domains.

Khishfe (2008) reported similar results regarding the effect of the context of the questions in children's ideas about the tentativeness of scientific knowledge. She used two similar questions to the ones in the current study to examine the students' views of tentative NOS. One question about dinosaurs was the same, but other question was about atom. She reported that a majority of the students had the misconception of "knowing is seeing" and students thought that in order to know and be sure about the structure of the atom or the way dinosaurs looked, scientists have to see atom and dinosaurs. Thus, it can be said that the context of the scientific knowledge was an important factor for the children in determining the tentativeness of scientific knowledge. This idea is somewhat in accordance with reality. Sandoval (2005) proposed that scientific knowledge varies in its degree of certainty and some scientific knowledge cannot be tentative at all, whereas some can be quite tentative. Tentativeness of scientific knowledge is a complex issue. Although all scientific knowledge is tentative, the degree of tentativeness depends on many factors such as the subject area, amount of research conducted in this area, number of researchers conducting research in this area, etc. Thus, the children would have been felt the same complexity in deciding the tentativeness of scientific knowledge. Some researchers (Khishfe, 2008; Khishfe \& Lederman, 2006; Lederman \& O'Malley, 1990) interpreted this situation as the children being in transition and thus do not fully comprehend the tentative NOS. However, as children learn more about tentativeness of scientific knowledge in different areas, they would reach the generalization that all kinds of scientific knowledge are tentative, but reliable regardless of domain. Nevertheless, the science camp program affected most of the children's views of tentativeness of scientific knowledge positively in reaching general idea about tentativeness or progressing toward this ideal end point.

It was interesting that no child talked about data at the beginning of the science camp, but most of the children realized the role of data and importance of the amount of data in explaining the change in scientific knowledge at the end of the science camp. The children learned the process of the construction of scientific knowledge through guided-inquiry activities. Thus, they learned the process of the construction of scientific knowledge from raw data to conclusion. Knowing the construction of scientific knowledge from first-hand data would have helped them better realized the tentativeness of the scientific knowledge. For example, as it was evident in the quotes from the post-camp data throughout the paper, the children realized that scientific knowledge is based on data and thus any change in data might affect the scientific knowledge. Thus, it is evident that understanding empirical nature of science is a key issue in understanding the tentativeness of scientific knowledge. As Lederman and O'Malley (1990) stated, the tentativeness of scientific knowledge is not limited to the recognition of changing scientific knowledge through history. Rather, science draws its tentative and revisionary characteristics from a complex interaction of its 
assumptions, theories, and methods for construction of scientific knowledge. Duschl (2009) also stated that it was better to express that scientific knowledge is responsive rather than tentative. Scientific knowledge is responsive to the change in data and most of the children were able to explain the tentativeness of scientific knowledge from this perspective.

There were some differences between the children's ideas about the tentativeness of scientific knowledge in science books and their ideas about the tentativeness of scientific knowledge about dinosaurs and meteorology. Although there were seven children who did not accept the tentativeness of scientific knowledge in science books, there was only one child who did not accept tentativeness of scientific knowledge about dinosaurs and meteorology at the beginning of the science camp. It was inferred that the children saw scientific knowledge in science books as more certain than scientific knowledge about dinosaurs and meteorology. Text-book based teaching imposes the impression on children that knowledge in textbooks is certain. This could affect their thinking about the tentativeness of the scientific knowledge in science books toward seeing the scientific knowledge as less subject to change than the scientific knowledge about dinosaurs and meteorology. In addition to this difference at the beginning of the science camp, the progress of the children's understanding of the tentativeness of scientific knowledge in science books was faster than their progress of understanding the tentativeness of scientific knowledge about dinosaurs and meteorology. The number of children in the top category (data-based explanations) was fifteen in the science books question; whereas that of dinosaurs and meteorology questions was only five. The science books questions asked if the scientific knowledge would change in the future. Thus, it is asked in general for scientific knowledge. However, the other two questions about dinosaurs and meteorology were content-embedded questions and elicited the children's ideas about tentativeness of scientific knowledge in a context (Khishfe \& Abd-El-Khalick, 2002). The children's understanding of the tentativeness of scientific knowledge in general would be easier than understanding the tentativeness of scientific knowledge in a specific area.

The positive change in the children' ideas about tentative NOS proved the effectiveness of the science camp program. The main methodology of the science camp program was a combination of explicit reflective guided-inquiry to learn scientific process and making NOS aspects explicit throughout the inquiry process, and explicit reflective NOS activities to introduce NOS aspects in a more explicit way. The positive change in the children's understanding of the tentative nature of scientific knowledge reported in the current study has contributed to the evidence that proves the effectiveness of this methodology. Explicit NOS activities were proved to be effective in developing children's ideas about NOS (Khishfe, 2008; Khishfe \& Abd-El-Khalick, 2002; Khishfe \& Lederman, 2006). Explicit inquiry was also found to be effective in introducing NOS aspects (Khishfe, 2008; Lederman \& Lederman, 2004; Schwartz, Lederman \& Crawford, 2004). The study applied a combination of explicit inquiry and NOS activities according to Clough (2006) suggestions and proved that their combination was also effective in introducing NOS aspects.

\section{Conclusion}

The purpose of the study was to determine effectiveness of a summer science camp program on children's views of tentative aspect of NOS. Based on the results of the study, it could be 
concluded that the science camp program was effective in developing children's views about tentative NOS.

Inquiry in the nature is an authentic way for introducing science to children. The children worked as scientists at the science camp and learned about NOS from their experiences. Explicit NOS activities made NOS aspects even more explicit. Therefore, we recommend combining guided-inquiry and explicit NOS activities in introducing the tentativeness of scientific knowledge.

\section{Limitations of the Study}

The limitation of this study would be short duration (ten days) of the science camp. But, science camps would not be longer because of expenses and busy work load for the team. On the other hand, instruction sessions in the science camp were intense; explicit NOS and explicit reflective inquiry sessions add up to approximately 40 hours.

\section{References}

Abd-El-Khalick, F. (2001). Embedding the nature of science instruction in preservice elementary science courses: Abonding scientism, but... Journal of Science Teacher Education, 12(3), 215-233. http://dx.doi.org/10.1023/A:1016720417219

Abd-El-Khalick, F., \& Lederman, N. (2000). Improving science teachers' conceptions of nature of science: a critical review of the literature. International Journal of Science Education, 22(7), 665-701. http://dx.doi.org/10.1080/09500690050044044

Akerson, V. L. \& Donnely, L. A. (2010) Teaching nature of science to K-2 students: what understandings can they attain?, International Journal of Science Education, 32(1), 97-124.http://dx.doi.org/10.1080/09500690902717283

Akerson, V.L., \& Abd-El-Khalick, F. (2005). "How should I know what scientists do? I am just a kid”: fourth-grade students' conceptions of nature of science. Journal of Elementary Science Education, 17(1), 1-11. http://dx.doi.org/10.1007/BF03174669

Akerson, V.L., Abd-El-Khalick,F., \& Lederman, N.G. (2000). Influence of a reflective explicit activity-based approach on elementary teachers' conceptions of nature of science. Journal of $\begin{array}{llll}\text { Research in } \quad \text { Science } & \text { 295-317. }\end{array}$ http://dx.doi.org/10.1002/(SICI)1098-2736(200004)37:4<295::AID-TEA2>3.3.CO;2-U

Akerson, V. L., \& Volrich, M. L. (2006) Teaching nature of science explicitly in a first-grade internship setting, Journal of Research in Science Teaching, 43, 4, 377-394.http://dx.doi.org/10.1002/tea.20132

Chambers, D. W. (1983) Stereotypical images of the scientist: The Draw-Scientist Test. Science Education, 67(2), 255-265. http://dx.doi.org/10.1002/sce.3730670213

Clough, M. P. (2006) Learners' responses to the demands of conceptual change: considerations for effective nature of science instruction, Science \& Education, 15, 463-494. http://dx.doi.org/10.1007/s11191-005-4846-7 
Duschl, R. (2009). Students' conceptions in science: Investigating ideas, activities and interactions. A symposium presented at Yeditepe University, Istanbul, Turkey, Agust 2009.

Khishfe, R. (2008). The development of seventh graders' views of nature of science. Journal of Research in Science Teaching, 45(4), 470-496. http://dx.doi.org/10.1002/tea.20230

Khishfe, R., \& Abd-El-Khalick, F. (2002). Influence of explicit and reflective versus implicit inquiry-oriented instruction on sixth graders' views of nature of science. Journal of Research in Science Teaching, 39(7), 551-578. http://dx.doi.org/10.1002/tea.10036

Khishfe, R., \& Lederman, N. (2006). Teaching Nature of Science within a Controversial Topic: Integrated versus Nonintegrated. Journal of Research in Science Teaching, 43(4), 395-418. http://dx.doi.org/10.1002/tea.20137

Lecompte, M. D., \& Preissle, J., (1993). Ethnography and Qualitative Design in Educational Research (2nd Ed). San Diego: Academic Press.

Lederman, J. S., \& Khishfe, R. (2002) Views of nature of science, Form D. Unpublished paper: Illinois Institute of Technology, Chicago, IL.

Lederman, J. S., \& Lederman, N. G. (2004) Early Elementary Students' and Teacher's Understandings of Nature of Science and Scientific Inquiry: Lessons Learned From Project ICAN. A paper presented at the Annual Meeting of the National Association for Research in Science Teaching, Vancouver, British Columbia, April 2004.

Lederman, N. G. (1992). Students' and teachers' conceptions about the nature of science: A review of the research. Journal of Research in Science Teaching, 29, 331-359. http://dx.doi.org/10.1002/tea.3660290404

Lederman, N.G. (2007) Nature of science: past, present, and future. In Abell, S. K., Lederman, N. G. (Eds), Handbook of Research on Science Education, pp. 831-879. New Jersey, Lawrence Erlbaum Associates.

Lederman, N. G., \& Abd-El-Khalick, F., (1998). Avoiding De-Natured Science: Activities That Promote Understanding of the Nature of Science. In W. McComas (Ed.), The Nature of Science in Science Education: Rationales and Strategies, pp.83-126. Dordrecht, The Netherlands: Kluwer Academic Publishers.

Lederman, N.G., Abd-El-Khalick,F., Bell, R.L. ve Schwartz, R.S. (2002) Views of nature of science questionnaire: Toward valid and meaningful assessment of learners' conceptions of nature of science, Journal of Research in Science Teaching,39(6), 497-521. http://dx.doi.org/10.1002/tea.10034

Lederman, N. G., \& O’Malley, M. (1990). Students’ perceptions of tentativeness in science: development, use, and sources of change. Science Education, 74, 225-239. http://dx.doi.org/10.1002/sce.3730740207

Liu, S. Y., \& Lederman, N. G. (2002). Taiwanese students’ views of nature of science. School Science and Mathematics, 102, 114-122. 
http://dx.doi.org/10.1111/j.1949-8594.2002.tb17905.x

Meichtry,Y.J. (1992). Influencing student understanding of the nature of science: Data from a case of curriculum development. Journal of Research in Science Teaching, 29, 389-407. http://dx.doi.org/10.1002/tea.3660290407

Sandoval,W.A. (2005). Understanding students' practical epistomologies and their influence on learning through inquiry. Science Education, 89, 634-656. http://dx.doi.org/10.1002/sce.20065

Schwartz, R.S., Lederman, N.G., \& Crawford, B.A. (2004). Developing views of NOS in an authentic context: an explicit approach to bridging the gap between the NOS and scientific inquiry. Science Education, 88, 610-645. http://dx.doi.org/10.1002/sce.10128

Schibeci, R. A. (1989). Home, school and peer group influences on student attitudes and achievement in science. Science Education, 73(1), 13-24. http://dx.doi.org/10.1002/sce.3730730103

Urhahne, D.; Kremer, K.; \& Mayer, J. (2011). Conceptions of the nature of science-Are they general or context specific? International Journal of Science and Mathematics Education, 9, 707-730. http://dx.doi.org/10.1007/s10763-010-9233-4 